\title{
Research on the Influence of Abutment Expansion Joint on Dynamic Performance of a Bridge
}

\author{
WANG Tianli ${ }^{1, a}$, YAN Wen ${ }^{1, b}$, WANG Minli ${ }^{2, c}$ \\ ${ }^{1}$ Dept. of Civil engineering. Xi'an University of Architecture \& Technology. Xi'an. China. \\ ${ }^{2}$ Northwest Institute of Forest Inventory. Planning and Design. State Forestry Administration. Xi'an. \\ China. \\ aemail: Wangtldq@xauat.edu.cn, ${ }^{\mathrm{b} e m a i l: 421541901 @ q q . c o m},{ }^{\mathrm{c} e m a i l: 271952682 @ q q . c o m}$
}

\begin{abstract}
Keywords: bridge engineer; abutment expansion joint; space finite element mode; nonlinear time history analysis method; dynamic performance

Abstract. Aiming at pounding damage at expansion joint in a bridge under earthquake, the paper puts forward the new structure to cancel the expansion joint at abutment but reserve the expansion joint at pier between the two units in a bridge. Two different space finite element models of a bridge are built. Using nonlinear time history analysis method, the paper contrasts the difference of the dynamic characteristics and the seismic response between the bridges cancelled the abutment expansion joints and reversed the abutment expansion joints. The result indicates that the structure of cancelled the expansion joints at abutment can effectively improve the dynamic performance of the bridge structure.
\end{abstract}

\section{Introduction}

In recent years highway construction has obtained great development in China, multi-unit (where one continuous girder is defined as one unit) bridge structure joined by expansion joints has been used widely in order to meet the requirement of bridge length. Generally the expansion joint need cross the bridge in breadth direction so that it has free distortion in load, temperature change, the concrete shrinkage, creep and so on. Therefore the expansion joint is the weak point of a bridge, and it needs to be repaired or replaced every 10 20 years, otherwise the whole bridge's using life will be significantly shortened. Investigation shows that almost all highways in the world exists those problems in different extent. Many bridge engineers put forward: "the best expansion joint structure is jointless"[1]. If we can design and build jointless bridges, the problem of expansion joints destroy will be fundamentally solved. But, with expansion joint cancelled, the length of a bridge is shortened sharply due to structure deformation. At present, the jointless bridge structure is suitable for a bridge whose length is less than $100 \mathrm{~m}$. Therefore, it has been widely adopted that a long bridge of hundreds meters joined by expansion joint.

In order to improve the applicability of jointless structure, the authors put forward to cancel the expansion joint at abutment but reserve the expansion joint at pier between the two units, and study its dynamic characteristics and the seismic response.

\section{Engineering Background}

The bridge comes from the Sanhuan Interchange project in Xi'an. It is made up of two units, unit one is $4 \times 25(\mathrm{~m})$, unit two is $5 \times 25(\mathrm{~m})$, and lies in a straight line. The superstructure adopts C50 Prestressed Reinforced Concrete box girders (1.2m high, equal section), and the substructure is C30 Reinforced Concrete columnar pier, thin-wall abutment and bored pile. The PTFE sliding rubber bearing is installed on $4^{\#}$ pier table, $0^{\#}$ and $9^{\#}$ abutments table, and the rubber pad bearing is installed on the rest pier tables. Here two theoretical space models are built. Model 1 is made up of unit one, pier table FM-80 expansion joint and unit two. Model 2 is made up of abutment table FM-80 expansion joint, unit one, pier table FM-80 expansion joint, unit two, and $9^{\#}$ abutment table FM-80 expansion joint. Model elevation graph and plane graph are shown in Fig. 1. 

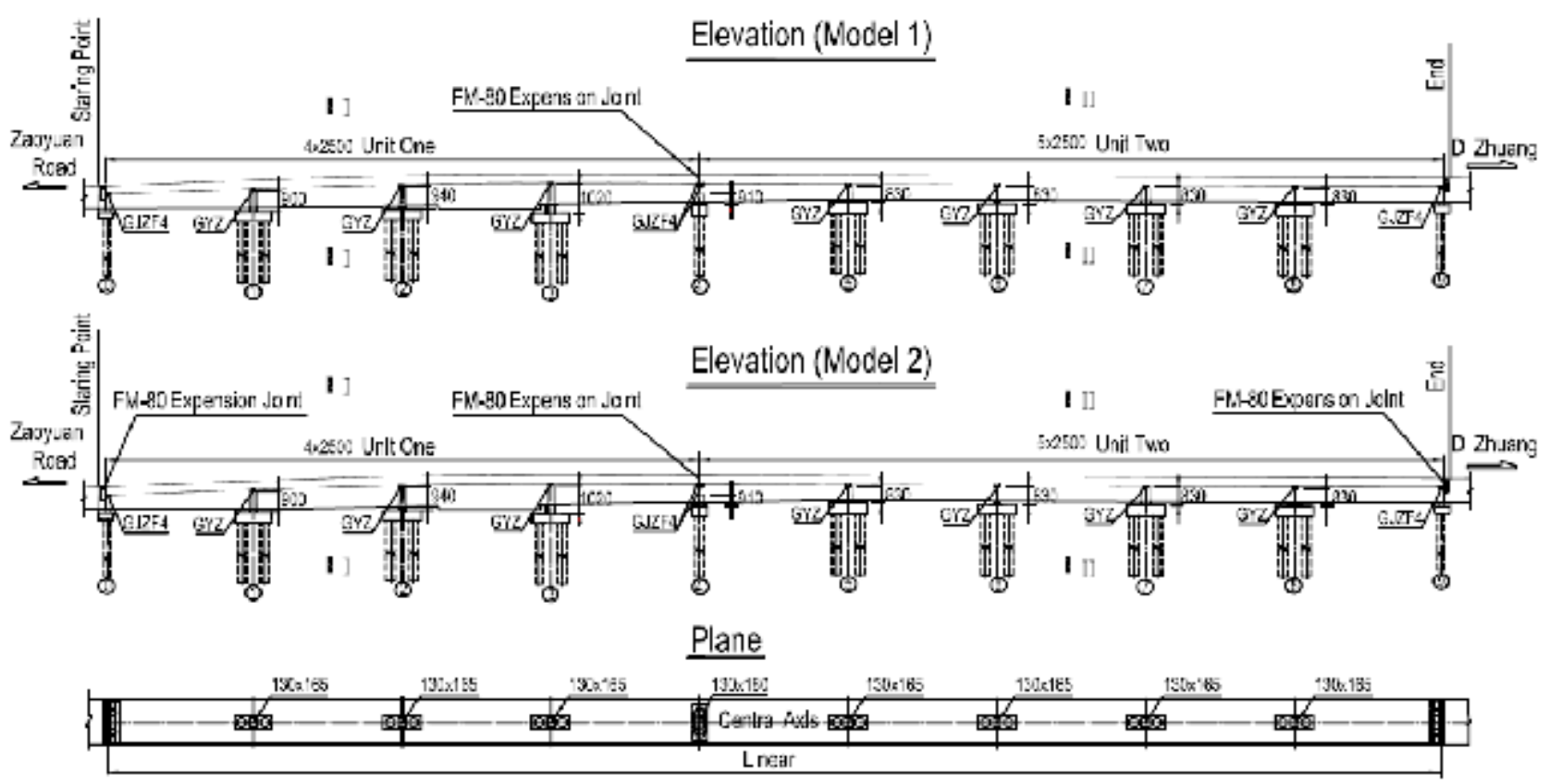

Fig. 1, Elevation and Plan of the bridge

\section{Finite Element Model}

There are many types of bearing, where rubber bearing is widely used in engineering. The spring element is used to simulate rubber pad bearing and PTFE sliding rubber bearing. The hysteresis curve of rubber pad bearing [2] is in long and narrow shape, and it can be approximated as linear, shown in Fig. 2(a). The hysteresis curve of PTFE sliding rubber bearing [2] is a stress-strain relation of perfect elastic-plastic material, shown in Fig. 2(b).

The Kelvin contact element is used to simulate the pounding response of expansion joints under earthquake. The main beam is simplified as rigid body, and the interaction characteristics of pounding and energy dissipation characteristics at expansion joint is represented by the equivalent viscous damper and spring elements. Contact element [3] is described as the following model in Fig. 3, and restoring force curve of the elastic spring is shown.

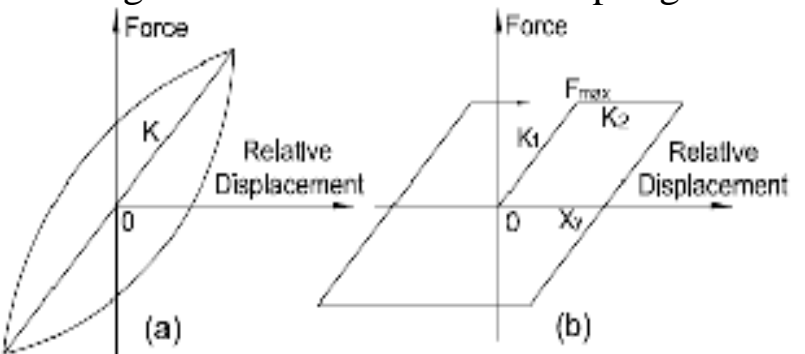

Fig. 2, Dynamic hysteresis curve

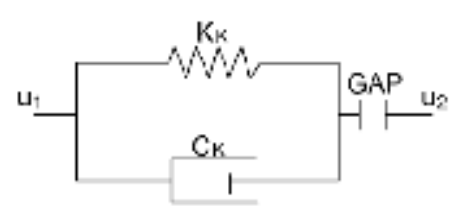

Fig. 3, Kelvin model

$$
\text { Pounding force: } F=\left\{\begin{array}{lll}
0 & \Delta<0 & \text { no collision } \\
\left.K_{k}\left(u_{1}-u_{2}-g_{p}\right)+C_{k}(\alpha)-1 \&\right) & \Delta \geq 0 & \text { collision }
\end{array}\right.
$$

Where: $g_{p}$ is the initial gap, $\mu_{1}-\mu_{2}$ is the relative displacement of the beams at both sides of the expansion joint, $K_{k}$ is the pounding stiffness [4], $C_{k}$ is the pounding damping coefficient.

This paper focuses on the dynamic performance of the bridge structure, the key of the model is to accurately simulate the stiffness and mass of the bridge, so the 3-D truss model is used due to the machine's cost. The beam and pier is simulated as a nonlinear 3-D beam element named as Beam189 in ANSYS (the element type, the same below), the expansion joint is as Combin40, the shear stiffness of Rubber pad bearing is as Combin14, the PTFE sliding rubber bearing is as Combin40, foundation deformation in seismic is not considered and simplified as consolidation. The full-bridge space finite element models, in Fig. 1, are built and used for dynamic performance study. 


\section{Dynamic analysis}

Modal analysis of the above two models is completed. Rayleigh damping assumption is adopted here. For the concrete structure, damping ratio $\xi=0.05 . \omega_{1}$ is structure basic frequency and $\omega_{\mathrm{m}}$ is modal frequency whose contribution is maximal among the first 50 vibration modes. Linear combination coefficients $\mathrm{a}_{0}$ and $\mathrm{a}_{1}$ of mass matrix and stiffness matrix is obtained for dynamic time history analysis. The top 5 order vibration modes are listed in Table 1.

$$
[C]=a_{0}[M]+a_{1}[K],\left\{\begin{array}{l}
a_{0} \\
a_{1}
\end{array}\right\}=\frac{2 \xi}{\omega_{1}+\omega_{m}}\left\{\begin{array}{l}
\omega_{1} \omega_{m} \\
1
\end{array}\right\}
$$

Table 1. Dynamic analysis

\begin{tabular}{|c|c|c|c|c|c|c|c|}
\hline $\begin{array}{c}\text { Modal } \\
\text { Analysis }\end{array}$ & $\boldsymbol{\omega}_{\mathbf{1}}(\mathbf{H z})$ & $\boldsymbol{\omega}_{\mathbf{2}}(\mathbf{H z})$ & $\boldsymbol{\omega}_{\mathbf{3}}(\mathbf{H z})$ & $\boldsymbol{\omega}_{\mathbf{4}}(\mathbf{H z})$ & $\boldsymbol{\omega}_{\mathbf{5}}(\mathbf{H z})$ & $\boldsymbol{a}_{\boldsymbol{1}}$ & $\boldsymbol{a}_{\boldsymbol{0}}$ \\
\hline Model 1 & $1.9367 \mathrm{e}-6$ & $0.42155 \mathrm{e}-2$ & 0.8639 & 0.90824 & 1.07782 & 0.11575259 & $1.9367 \mathrm{e}-7$ \\
\hline Model 2 & $1.6626 \mathrm{e}-6$ & $0.42154 \mathrm{e}-2$ & 0.84098 & 0.86391 & 0.88303 & 0.1189087 & $1.6626 \mathrm{e}-7$ \\
\hline
\end{tabular}

From the table 1, it can be see that the frequency of the model 1 is larger than that of model 2 . It shows that for the bridge that has same units, cancelled the expansion joint at the abutment is helpful to increase its stiffness. It is suitable for a multi-unit long bridge which has smaller stiffness.

\section{Seismic input condition}

Taft seismic acceleration record ( $\mathrm{X}$ direction, $\mathrm{Y}$ direction and $\mathrm{Z}$ direction) in 1952 and Tianjing seismic acceleration record(X direction, $Y$ direction and $\mathrm{Z}$ direction) in 1976 are adopted as the input of time history analysis, whose correlation coefficient in same direction is less than 0.1 and duration is 12s. According to the combination principle of three kinds of single dimensional, two dimensional $(\mathrm{X}+\mathrm{Y})$ and three-dimensional $(\mathrm{X}+\mathrm{Y}+\mathrm{Z})$, two groups of seismic acceleration records are constituted 8 kinds of earthquake conditions.

\section{Seismic response analysis}

The extreme internal force of moment $(\mathrm{M})$ and shear $(\mathrm{Q})$ in the middle of the second span (I-I section, in fig. 1) are selected as representative of the internal force of the main beam in the unit one $(4 \times 25 \mathrm{~m})$ superstructure. Those in the middle of the seventh span (II-II section, in fig. 1) are selected as representative of the unit two $(5 \times 25 \mathrm{~m})$ superstructure. They are shown in table 2 .

Due to space limitations, the extreme internal force moment $(\mathrm{M})$ and shear $(\mathrm{Q})$ in the bottom of $3^{\#}$ pier are selected as representative of the internal force of the pier in the unit one substructure. Those in the bottom of $4^{\#}$ pier are selected as representative of the pier of the substructure at the expansion joint between two units. Those in the bottom of $5^{\#}$ pier are selected as representative of the pier in the unit two substructure. They are shown in table 2.

The extreme pounding force (F) and corresponding displacement (D) at the expansion joint are also shown in table 2. 
Table 2. Seismic response analysis

\begin{tabular}{|c|c|c|c|c|c|c|c|c|c|}
\hline \multirow{3}{*}{ Beam } & \multicolumn{5}{|c|}{ Model 1} & \multicolumn{4}{|c|}{ Model 2} \\
\hline & \multicolumn{2}{|c|}{ I-I section } & \multicolumn{3}{|c|}{ II-II section } & \multicolumn{2}{|c|}{ I-I section } & \multicolumn{2}{|c|}{ II-II section } \\
\hline & $\mathrm{M}(\mathrm{kN} . \mathrm{m})$ & $\mathrm{Q}(\mathrm{kN})$ & & & $\mathrm{Q}(\mathrm{k}$ & $\mathrm{M}(\mathrm{kN} . \mathrm{m})$ & $\mathrm{Q}(\mathrm{kN})$ & $\mathrm{M}(\mathrm{kN} . \mathrm{m})$ & $\mathrm{Q}(\mathrm{kN})$ \\
\hline Force & 45133.3 & 6555.5 & & & 6605 & 98512.9 & 149858 & 119081 & 157906 \\
\hline \multirow{3}{*}{ Pier } & \multicolumn{9}{|c|}{ Model 1} \\
\hline & \multicolumn{3}{|c|}{ the bottom of $3^{\#}$ pier } & \multicolumn{3}{|c|}{ the bottom of $4^{\#}$ pier } & \multicolumn{3}{|c|}{ the bottom of $5^{\#}$ pier } \\
\hline & $\mathrm{M}(\mathrm{kN} . \mathrm{m})$ & & & & J.m) & $\mathrm{Q}(\mathrm{kN})$ & $\mathrm{M}(\mathrm{kN}$ & & $2(\mathrm{kN})$ \\
\hline Force & 22549.4 & & & & & 865.7 & 1956 & & 355.2 \\
\hline \multirow{3}{*}{ Pier } & \multicolumn{9}{|c|}{ Model 2} \\
\hline & \multicolumn{3}{|c|}{ the bottom of $3^{\#}$ pier } & \multicolumn{3}{|c|}{ the bottom of $4^{\#}$ pier } & \multicolumn{3}{|c|}{ the bottom of $5^{\#}$ pier } \\
\hline & $\mathrm{M}(\mathrm{kN} . \mathrm{m})$ & & & & J.m) & $\mathrm{Q}(\mathrm{kN})$ & $\mathrm{M}(\mathrm{kN}$ & & $\mathrm{Q}(\mathrm{kN})$ \\
\hline Force & 22082.4 & & & & & 768.8 & 1769 & & 2134.6 \\
\hline \multirow{3}{*}{$\begin{array}{c}\text { Expansion } \\
\text { joint }\end{array}$} & \multicolumn{9}{|c|}{ Model 1} \\
\hline & \multicolumn{3}{|c|}{$0^{\#}$ abutment } & \multicolumn{3}{|c|}{$4^{\#}$ pier } & \multicolumn{3}{|c|}{$9^{\#}$ abutment } \\
\hline & $\mathrm{F}(\mathrm{kN})$ & & & & & $\mathrm{D}(\mathrm{mm})$ & $\mathrm{F}(\mathrm{k}$ & & $(\mathrm{mm})$ \\
\hline Value & 10275.7 & & & & & 38.4 & 1265 & & 0 \\
\hline \multirow{3}{*}{$\begin{array}{l}\text { Expansion } \\
\text { joint }\end{array}$} & \multicolumn{9}{|c|}{ Model 2} \\
\hline & \multicolumn{3}{|c|}{$0^{\#}$ abutment } & \multicolumn{3}{|c|}{$4^{\#}$ pier } & \multicolumn{3}{|c|}{$9^{\#}$ abutment } \\
\hline & $\mathrm{F}(\mathrm{kN})$ & & & & & $\mathrm{D}(\mathrm{mm})$ & $\mathrm{F}(\mathrm{k}$ & & $(\mathrm{mm})$ \\
\hline Value & 263772 & & & & & 178.3 & 5095 & & 337.3 \\
\hline
\end{tabular}

From the table2, it can be analyzed that the seismic response of the main beam in model 2 is much larger than that of model 1. For example, the shear response and moment response of the II-II section in model 2 is about 20 times as much as that of model 1.

At the same time, cancelled the expansion device at abutment, which makes the model 1 of the seismic pounding response force and displacement are deeply reduced at the expansion joint. In model 1 the main girder and abutment is integrally connected, under the earthquake, the relative displacement at the abutment of $0^{\#}$ and $9^{\#}$ is zero, and the response at the expansion join of $4^{\#}$ pier is no more than the amount of the displacement from the expansion device (GAP=0.05m, in Fig. 3), so $4^{\#}$ pier joints seismic pounding force is zero.

But on the other hand, the seismic response force in the bottom of pier is lower about $10 \%$ in the model 2 than that of model 1.

\section{Conclusions}

With the above analysis summarized, the influence of abutment expansion joint on dynamic performance of a bridge structure can be listed as follows:

1. For a multi-unit long bridge joined by expansion joints, that has larger slender ratio and smaller stiffness, cancelling the abutment expansion joints can improve the structure stiffness and the dynamic performance.

2. Cancelling the abutment expansion joints makes the moment and shear force of the piers slightly increased. Special attention is needed in the design.

3. Cancelling the abutment expansion joints could effectively eliminate or decrease the seismic pounding response of expansion joints.

\section{Acknowledgements}

The authors would like to acknowledge National Natural Science Foundation of Chain (51078306, 51408453); Scientific Research Program Funded by Shaanxi Provincial Education Department (14JK1418); Natural Science Basic Research Plan in Shaanxi Province of China (2013JQ0007); and the Major Subject Construction Foundation of Shanxi province (No E01004) for their financial supports. 


\section{References}

[1] Chen Baochun, Zhuang Yizhou, Bruno Briseghella. Jointlless bridges. China Communication Press, 2013: 10 20 (in Chinese)

[2] JTG/T B02-01—2008. Guidelines for seismic design of highway bridges. China Communications Press, 2008:25 26 (in Chinese)

[3] Zuada Coelho B, Vervuurt A H J M, Peelen W H A, Leendertz J S. Dynamics of modular expansion joints: The Martinus Nijhoff Bridge. Engineering Structures. 2013,48: 144 154

[4] Wang Dongsheng, Feng Qimin, Wang Guoxin. Analysis model of pounding between adjacent bridge girders during earthquakes based on collinear impact between rods. Engineering Mechanics, 2004,21(2):157 165 (in Chinese) 